\title{
EFEITO DOS FUNGICIDAS METALAXIL E FENARIMOL NA MICROBIOTA DO SOLO
}

\author{
CÉLIA MARIA MAGANHOTTO DE SOUZA SILVA* \\ ELISABETH FRANCISCONI FAY** \\ ROSANA FARIA VIEIRA***
}

\begin{abstract}
Avaliou-se o efeito adverso dos fungicidas metalaxil e fenarimol na comunidade microbiana de solos sob cultivo de uva, provenientes da região de Petrolina, Pernambuco (Brasil). No experimento, conduzido em casa de vegetação, os solos foram suplementados com diferentes concentrações dos fungicidas, sendo avaliados os seguintes parâmetros microbiológicos: carbono da biomassa microbiana (Cmic), comprimento de hifas vivas, atividade hidrolítica do diacetato de fluoresceína (FDA), atividade enzimática da fosfatase ácida e atividade enzimática da desidrogenase. A adição dos fungicidas afetou negativamente o Cmic, o comprimento das hifas vivas e a atividade da desidrogenase, mas não demonstrou efeito adverso sobre o FDA e a atividade enzimática da fosfatase. O fenarimol mostrou-se mais tóxico que o metalaxil, sendo observado efeito transitório de ambos no solo.
\end{abstract}

PALAVRAS-CHAVE: FUNGICIDA; METALAXIL: FENARIMOL; MICROBIOTA DO SOLO.

* Biologa, MSc. Genética, Doutora em Microbiologia Ambiental, pesquisadora da Embrapa Meio Ambiente, Jaguariúna, SP (e-mail: celia@cnpma.embrapa.br).

** Farmacêutica-Bioquímica, MSc. Microbiologia Ambiental, pesquisadora da Embrapa Meio Ambiente (e-mail: bethfay@cnpma.embrapa.br).

*** Engenheira Agrônoma, MSc. Microbiologia Agrícola, Doutora em Solos e Nutrição de Plantas, pesquisadora da Embrapa Meio Ambiente (e-mail: rosana@cnpma.embrapa.br). 


\section{INTRODUÇÃO}

Na região semi-árida brasileira está concentrada grande parte da fruticultura do país. As práticas agrícolas utilizadas nessas áreas podem afetar o equilíbrio do ecossistema solo como, por exemplo, no caso do uso de agrotóxicos. Esses compostos orgânicos exercem papel benéfico na produtividade agrícola, no entanto são potenciais poluidores ambientais. Os agrotóxicos chegam ao solo por meio da aplicação direta e também como resultado de atividades indiretas. Uma vez no solo, normalmente afetam os processos bioquímicos e microbiológicos. Apesar do uso dos fungicidas constituir prática comum no controle de doenças de plantas, ainda são poucas as informações sobre o prejuízo ambiental causado por tais compostos.

O metalaxil e o fenarimol são dois fungicidas muito utilizados em fruticultura, principalmente no cultivo da uva. O fenarimol, derivado da pirimidina, bloqueia a biossíntese de esterol. O composto afeta os processos bioquímicos dessa biossíntese, sendo mais comum a demetilação do C-14 durante a conversão de lanosterol para ergosterol ou esterol funcionalmente equivalente (WEETE, 1989). O metalaxil é o mais ativo dos fungicidas fenilamidas e inibe a síntese do RNA ribossomal, interferindo na síntese de proteínas (METALAXYL, 2004). Esses compostos estão entre os mais utilizados no mundo e é importante considerar seus possíveis impactos na saúde e qualidade do solo. A pesquisa da interferência desses fungicidas nas propriedades biológicas e bioquímicas do solo, relacionadas à qualidade dos agroecossistemas, restringe-se a alguns poucos trabalhos, principalmente quando se considera solos de regiões áridas. Tais solos são difíceis de recuperar após os efeitos do uso e/ou manejo inadequados, o que pode provocar permanente degradação e perda de produtividade (PASCUAL et al., 2000).

O objetivo deste trabalho foi avaliar o efeito dos fungicidas metalaxil e fenarimol na microbiota dos solos da região semi-árida.

\section{MATERIAL E MÉTODOS}

O experimento foi conduzido em casa-de-vegetação, na Embrapa Meio Ambiente, localizada em Jaguariúna, estado de São Paulo, Brasil. Utilizou-se solo coletado em plantio comercial de uva na região de Petrolina, PE, classificado como latossolo vermelho-amarelo, textura arenosa, com as seguintes características físicas e químicas: $\mathrm{pH}\left(\mathrm{H}_{2} 0\right) 5,4$; capacidade de troca catiônica $19,4 \mathrm{mmol}_{\mathrm{C}}$ $\mathrm{dm}^{-3}$; matéria orgânica 9,3 $\mathrm{g} \mathrm{dm}^{-3}$; argila $142,1 \mathrm{~g} \mathrm{~kg}^{-1}$, areia $765,1 \mathrm{~g} \mathrm{~kg}^{-1}$ e silte $82,7 \mathrm{~g} \mathrm{~kg}^{-1}$.

No laboratório colocou-se o solo em caixas plásticas brancas, sem drenagem, com capacidade para $4 \mathrm{~kg}$, as quais constituíram as unidades experimentais. Corrigiu-se a umidade do solo para 60$70 \%$ da capacidade de campo, mantendo-a constante por meio de pesagens periódicas até o final do período experimental. Após período de repouso de sete dias, os solos foram suplementados com os fungicidas metalaxil ( 3 e $30 \mu \mathrm{g} \mathrm{g}^{-1}$ de solo) e fenarimol ( 0,12 e $1,2 \mu \mathrm{g} \mathrm{g}^{-1}$ de solo). Solos sem adição dos fungicidas foram utilizados como controle. Os compostos orgânicos foram aplicados com volume de água suficiente para manter a umidade do solo em 60-70\% da capacidade de campo. As avaliações dos parâmetros microbiológicos ocorreram após 0, 7, 14, 21, 42 e 119 dias de incubação. Também monitorou-se a temperatura do solo que permaneceu entre 23 e $28^{\circ} \mathrm{C}$ durante o período experimental.

Avaliou-se o efeito dos fungicidas sobre a microbiota do solo pelos parâmetros carbono da biomassa microbiana (Cmic), comprimento de hifa viva, atividade hidrolítica do diacetato de fluoresceína (FDA) e atividades enzimáticas da desidrogenase e fosfatase ácida.

\subsection{CARBONO (C) DA BIOMASSA MICROBIANA}

O carbono $(\mathrm{C})$ da biomassa microbiana foi medido pelo método de extração-fumigação (VANCE, BROOKES e JENKINSON, 1987). Cinqüenta gramas de solo foram separadas em duas amostras de 
$25 \mathrm{~g}$, sendo uma amostra exposta ao clorofórmio por $24 \mathrm{~h}$ e então submetida à extração com $100 \mathrm{~mL}$ de $\mathrm{K}_{2} \mathrm{SO}_{4} 0,5 \mathrm{M}$. A outra amostra foi imediatamente submetida à extração. Determinou-se o $\mathrm{C}$ orgânico nos extratos por digestão com dicromato de potássio. Calculou-se o conteúdo do $\mathrm{C}$ da biomassa microbiana usando a seguinte relação:

$$
\mathrm{C} \text { mic }=2.64 . \mathrm{Ec}
$$

Na qual:

Ec $=$ C orgânico extraído do solo fumigado menos o C orgânico extraído do solo não-fumigado.

\subsection{COMPRIMENTO DE HIFAS VIVAS}

Avaliou-se o comprimento de hifas vivas de acordo com o método proposto por MELLONI e CARDOSO (1999) com algumas adaptações feitas por NOGUEIRA e CARDOSO (2000). Água sob pressão foi adicionada a $20 \mathrm{~g}$ de solo contidos em béquer de $500 \mathrm{~mL}$. Verteu-se a suspensão em peneiras de 0,71 e $0,25 \mathrm{~mm}$, montadas sobre funil e béquer de 2 litros. As peneiras foram lavadas com forte jato de água e a suspensão ( 1,5 litros) transferida para liquidificador, sendo agitada por 10 segundos em baixa velocidade para garantir a dispersão dos agregados. A mistura permaneceu em repouso por 2 minutos antes de ser lentamente vertida em peneira de 44 mesh. $O$ material retido nessa peneira foi suspenso em tampão fosfato ( $\left.\mathrm{pH} 7,4 ; \mathrm{KH}_{2} \mathrm{PO}_{4} 0,1 \mathrm{M}+\mathrm{NaOH} 0,1 \mathrm{M} ; 10 \mathrm{~mL}\right)$. Para a determinação do comprimento de hifas vivas, $5 \mathrm{~mL}$ dessa suspensão foi misturada com $5 \mathrm{~mL}$ da solução de diacetato de fluoresceína (FDA) (BLOEM et al.,1995). O FDA (5 mg) foi dissolvido em $2 \mathrm{~mL}$ de acetona (NOGUEIRA e CARDOSO, 2000). Após incubação em temperatura ambiente por 5 minutos as hifas foram colhidas por filtração em filtro Millipore quadriculado $(0,45 \mu \mathrm{m})$. Determinou-se o comprimento das hifas fluorescentes utilizando luz ultra-violeta emitida em microscópio epifluorescente. Para esse comprimento de onda utilizou-se filtro azul. O comprimento das hifas foi quantificado em 64 quadrados delineados no centro do filtro, com magnificação de $60 \mathrm{X}$. Calculou-se o comprimento de hifas vivas de acordo com a equação de Newman (NEWMAN, 1966):

$$
R=(\pi \cdot A \cdot n) / 2 \cdot H
$$

Na qual:

$\mathrm{R}=$ comprimento do micélio extra-radicular avaliado nos 64 campos do filtro Millipore $(\mathrm{mm})$;

$A=$ área do filtro;

$\mathrm{n}=$ número de intersecções das hifas sobre as linhas horizontais do 'gride' reticulado da ocular;

$\mathrm{H}=$ comprimento total das linhas horizontais do 'gride'.

\subsection{ATIVIDADE MICROBIANA TOTAL DO SUBSTRATO POR MEIO DA HIDRÓLISE DE DIACETATO DE FLUORESCEÍNA - FDA}

Para a determinação da hidrólise de FDA utilizou-se a metodologia descrita por BOEHM e HOITINK (1992). Amostras de $5 \mathrm{~g}$ de substrato de cada vaso foram colocadas em frascos de $250 \mathrm{~mL}$, juntamente com $20 \mathrm{~mL}$ de tampão fosfato de potássio $60 \mathrm{mM}\left(8,7 \mathrm{~g} \mathrm{de}_{2} \mathrm{HPO}_{4}\right.$ e $1,3 \mathrm{~g}$ de $\mathrm{KH}_{2} \mathrm{PO}_{4} \cdot \mathrm{L}^{-1}$ de água destilada; $\mathrm{pH} 7,6$ ). A reação de hidrólise de FDA (Sigma Chemical Co.) foi iniciada adicionandose $0,2 \mathrm{~mL}(400 \mu \mathrm{g})$ de solução estoque de FDA ( $2 \mathrm{mg} \mathrm{mL}^{-1}$ de acetona). As amostras foram incubadas por 20 minutos em agitador a $160 \mathrm{rpm}$ a $25 \stackrel{\circ}{ } \mathrm{C}$. Imediatamente após a retirada das amostras do agitador, a reação foi interrompida por meio da adição de $20 \mathrm{~mL}$ de acetona por frasco. A seguir, efetuou-se a filtragem em papel de filtro tipo Whatman no 1 , sendo os filtrados recolhidos em tubos de 
cultura. Logo após, determinou-se em espectrofotômetro a absorbância dos filtrados a $490 \mathrm{~nm}$. Para obter a quantidade de FDA hidrolizado foi determinada a curva-padrão, adicionando-se em tubos de ensaio com rosca, $5 \mathrm{~mL}$ de tampão fosfato e $0,100,200,300$ e $400 \mu \mathrm{L}$ de solução estoque de FDA, em duas repetições para cada concentração por tratamento. Posteriormente, os tubos foram tampados e levados ao banho-maria com água fervente por uma hora para hidrolisar o FDA. Após o resfriamento dos tubos, a solução de FDA hidrolizado foi colocada em frascos de $250 \mathrm{~mL}$ contendo $5 \mathrm{~g}$ do substrato e $15 \mathrm{~mL}$ de tampão fosfato, em duas repetições para cada tratamento. Seguiu-se a mesma metodologia descrita para a incubação, filtragem e leitura de absorbância das amostras. Com a equação da reta da curva-padrão obtida pela regressão linear entre o FDA hidrolizado e a absorbância calculou-se o FDA hidrolizado pelos microrganismos nos respectivos tratamentos, expressos em $\mu \mathrm{g} \mathrm{min}^{-1} \mathrm{~g}$ solo seco-1.

\subsection{ATIVIDADE ENZIMÁTICA DA FOSFATASE ÁCIDA}

A determinação da atividade da fosfatase seguiu o método descrito por ALEF, NANNIPIERI e TRAZAR-CEPEDA (1995). Ao solo (1 g) foram adicionados tampão maleato 0,1M (pH 6,5) para análise da fosfatase ácida e p-nitrofenil fosfato preparado na mesma solução tampão (1 mL). Incubou-se a mistura a $37^{\circ} \mathrm{C}$ por 1 hora. Após a incubação foi adicionado $\mathrm{CaCl}_{2} 0,5 \mathrm{M}(1 \mathrm{~mL})$ e $\mathrm{NaOH} 0,5 \mathrm{M}(4 \mathrm{~mL})$. Determinou-se o p-nitrofenol (PNP) formado em espectofotômetro a $400 \mathrm{~nm}$. Os resultados da atividade foram expressos como $\mu \mathrm{g}$ de $\mathrm{p}$-nitrofenol liberado em 1 hora $^{-1}{ }^{-1 e}$ solo.

\subsection{ATIVIDADE ENZIMÁTICA DA DESIDROGENASE}

Avaliou-se a atividade enzimática da desidrogenase no solo segundo a técnica descrita por ALEF (1995). Foram pesados $5 \mathrm{~g}$ de solo, com a umidade proveniente de campo, em tubos testes e misturados com $5 \mathrm{~mL}$ da solução de cloreto de trifenil tetrazólio (TTC) a $0,3 \%$. Os tubos foram selados e incubados no escuro por $24 \mathrm{~h}$ a $37^{\circ} \mathrm{C}$. Os tubos controles continham somente $5 \mathrm{~mL}$ de tampão Tris$\mathrm{HCl} 100 \mathrm{mM}$, sem o TTC. Decorrido o período de incubação, adicionaram-se $20 \mathrm{~mL}$ de metanol aos tubos, que foram agitados por 1 minuto e, posteriormente, centrifugados a $2000 \mathrm{rpm}$ por $10 \mathrm{~min}$. Mediu-se o trifenil formazan (TTF), formado pela redução do TTC, espectofotometricamente a $485 \mathrm{~nm}$ contra o branco.

\section{RESULTADOS E DISCUSSÃO}

Os efeitos dos fungicidas metalaxil e fenarimol sobre a microbiota de solos da região semi-árida brasileira são apresentados nas Figuras 1 e 2.

Os resultados obtidos para o parâmetro $C$ da biomassa microbiana, avaliado em diferentes períodos de incubação e para diferentes concentrações dos fungicidas em estudo, não demonstraram interação significativa entre tempo*tratamento. No entanto, o $\mathrm{Cmic}$ foi significativamente afetado pela dose aplicada e pelo tempo de exposição $(P<0,01 \%)$. Apesar do efeito negativo do metalaxil sobre esse parâmetro estar presente desde o início das avaliações, somente mostrou-se significativo a partir do $28^{\circ}$ dia (médias de 29,9 e 17,3 $\mu \mathrm{g} \mathrm{g}^{-1}$ de solo na menor e maior dose, respectivamente). Quando comparado ao controle, o tratamento com suplementação de $3 \mu \mathrm{g} \mathrm{g}^{-1}$ apresentou inibição de $28 \% \mathrm{e}$ $48 \%$ enquanto que na concentração mais alta $\left(30 \mu \mathrm{g} \mathrm{g}^{-1}\right)$ a inibição foi de $54 \%$ e $32 \%$ aos 28 e 42 dias respectivamente. Verificou-se recuperação da microbiota no final do período experimental (119 dias) com incremento de 41 e $81 \%$ em relação ao controle para a menor e maior dose, respectivamente, demonstrando provável aporte de nutrientes ou de $\mathrm{C}$ provenientes dos microrganismos afetados pelo fungicida.

Efeito negativo mais drástico foi observado no solo suplementado com fenarimol, quando comparado ao solo controle. Verificou-se inibição média significativa de $22 \%$ para o Cmic logo aos 7 
dias de avaliação nas duas concentrações utilizadas. Tal inibição permaneceu irreversível até os 42 dias de avaliação, com variação na biomassa no $28^{\circ}$ dia entre 6,3 e $38,3 \mu \mathrm{g} \mathrm{g}^{-1}$ de solo, correspondendo a 41 e $83,6 \%$ de inibição para as doses de 0,12 e $1,2 \mu \mathrm{g} \mathrm{g}^{-1}$, respectivamente. Após esse período observou-se lenta recuperação no $\mathrm{Cmic}$. No entanto, no $42^{\circ}$ dia ainda foi possível visualizar efeito negativo significativo do fenarimol sobre a microbiota (30 e 43\%) de acordo com o modelo doseresposta. Isto é, a dose mais alta exibiu efeito inibitório mais severo. Da mesma forma que para o metalaxil, aos 119 dias de incubação houve recuperação da comunidade microbiana.

\section{FIGURA 1 - EFEITO DO FUNGICIDA METALAXIL SOBRE ALGUNS PARAMETROS MICROBIOLOGICOS DO SOLO}
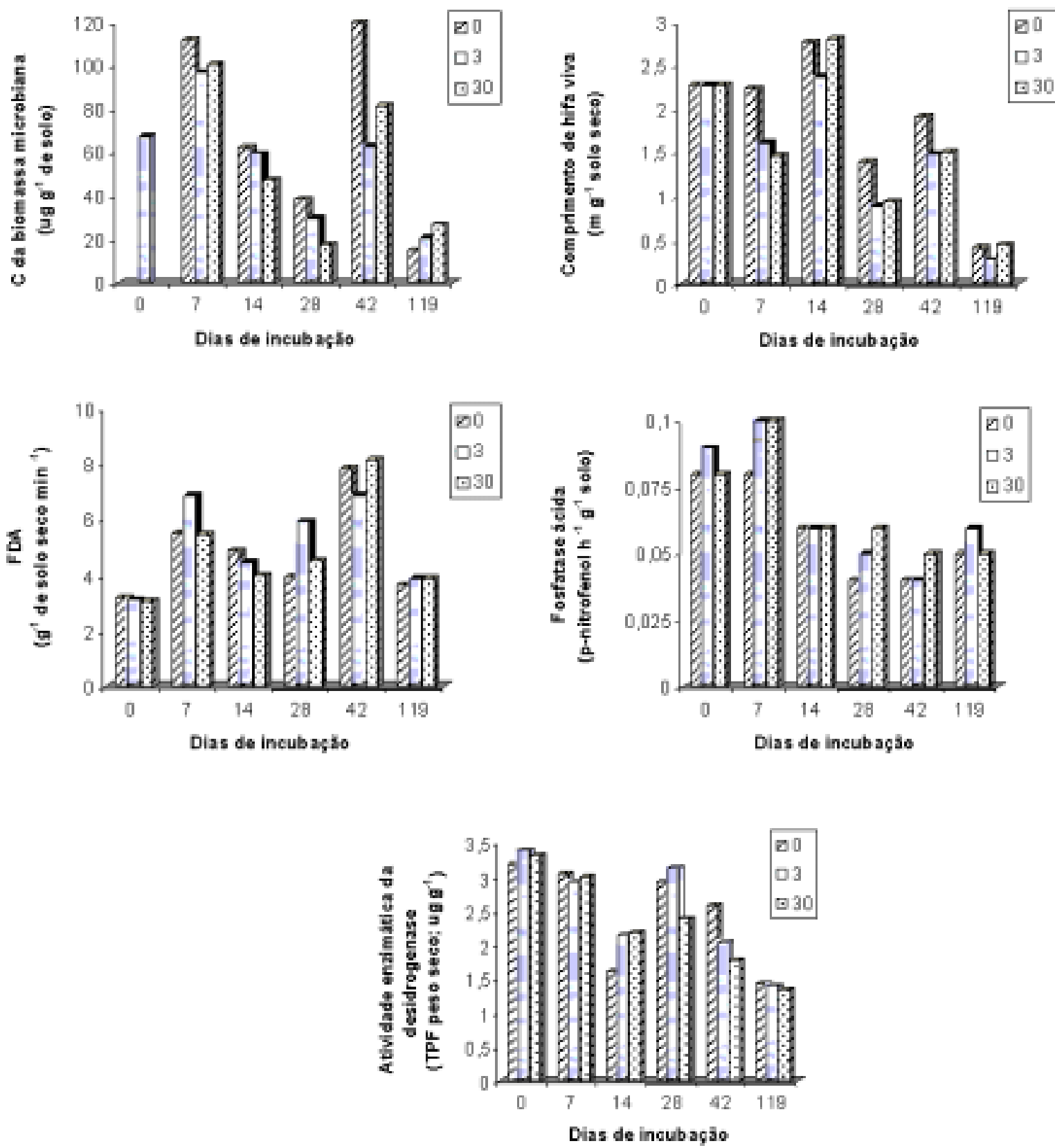

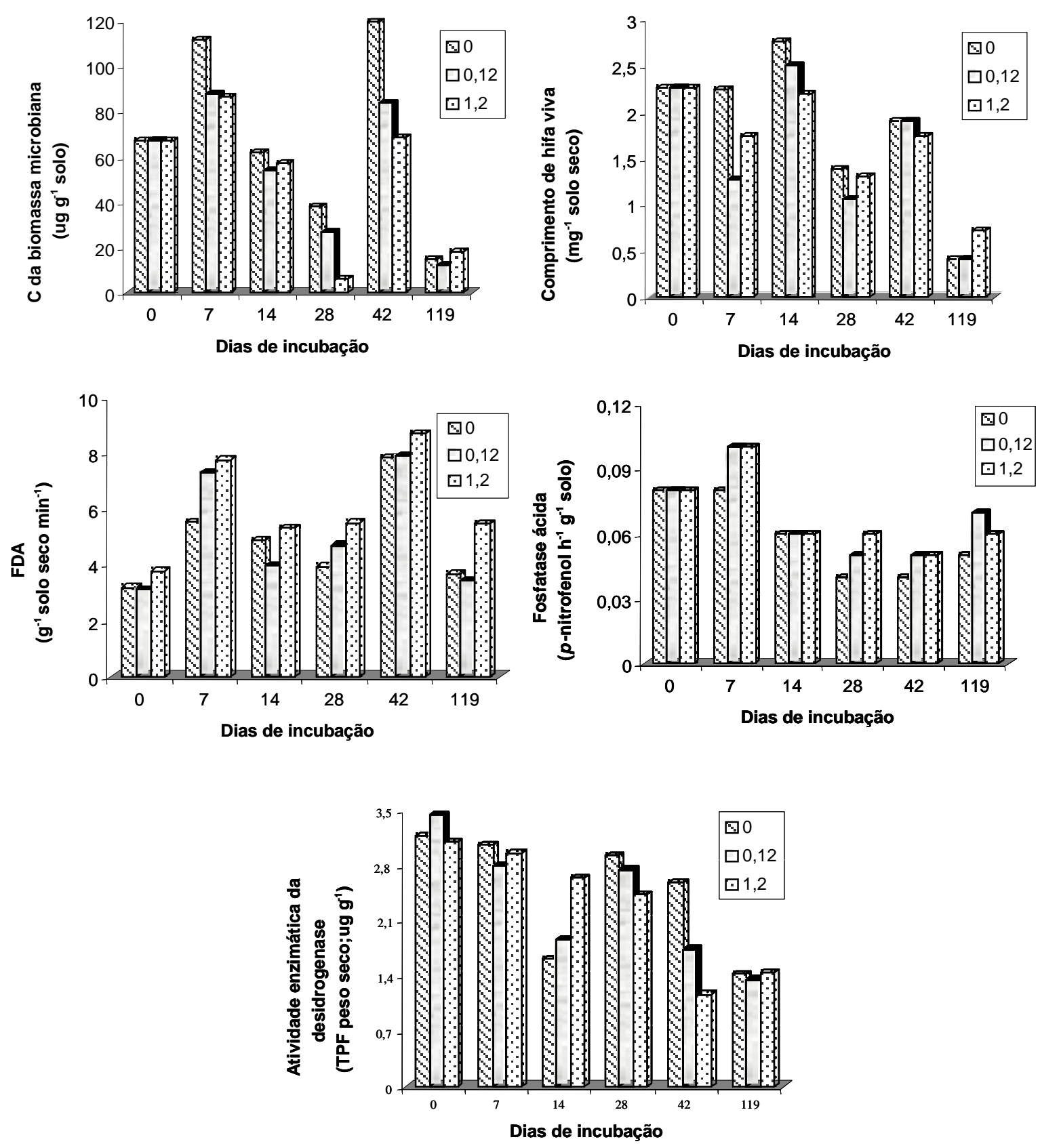

NANNIPIERI, GRECCO e CECCANTI (1990) afirmaram que em ecossistemas complexos como os das regiões áridas e semi-áridas, as medidas de parâmetros como a biomassa microbiana tornamse problemáticas devido ao desequilíbrio natural dessas áreas. No entanto, GARCIA, HÉRNANDES e COSTA (1994 e 1997) utilizaram esse parâmetro como indicador da atividade microbiológica de solos áridos do Mediterrâneo. Observaram que em solos áridos, o $\mathrm{Cmic}$ pode constituir indicador sensível das modificações no conteúdo de matéria orgânica quando relacionadas às atividades microbianas.

Neste estudo, o efeito negativo sobre o $\mathrm{Cmic}$ pode estar relacionado, principalmente, ao efeito sobre a comunidade fúngica como demonstra a correlação significativa $(P<0,01 \%)$ entre o Cmic e o comprimento de hifa viva. 
A estimativa da biomassa fúngica, baseada no comprimento de hifa viva, variou de 0,28 to $2,80 \mathrm{~m} \mathrm{~g}^{-1}$ solo seco (Figuras 1 e 2). $O$ efeito negativo do fungicida metalaxil sobre esse parâmetro, apesar de não-significativo, foi observado logo aos 7 dias de incubação, com inibição de 28 e $35 \%$ para a menor e maior dose aplicada, respectivamente, quando comparado ao tratamento testemunha. Da mesma forma que para o $\mathrm{Cmic}$, a inibição alcançou aos 28 dias patamares de $34 \% \mathrm{em}$ ambas as doses. Posteriormente, houve recuperação da biota fúngica.

Como para o $\mathrm{Cmic}$, o efeito da suplementação com o fungicida fenarimol foi mais drástico (Figura 2). Logo aos 7 dias de avaliação foi possível verificar inibições significativas ( $\pm 30 \%$ ) na microbiota fúngica. No entanto, esse efeito foi rápido, pois nas avaliações subseqüentes já foi observada recuperação dessa comunidade.

Considerando o comportamento apresentado pela microbiota pode-se inferir que ambos os fungicida reduziram a comunidade fúngica, ainda que temporariamente. No entanto, o metalaxil mostrouse menos tóxico aos fungos quando comparado ao fenarimol.

Neste trabalho evidenciou-se efeito transitório dos fungicidas, e a recuperação da comunidade microbiana no final do período experimental pode ter sido conseqüência da reativação da microbiota original. Também pode ter ocorrido aumento da população e da atividade das espécies microbianas resistentes, perda da competição pelos fungos inibidos pelo fungicida, ou utilização do fungicida como fonte de carbono por alguns microrganismos (VYAS, 1988; CHEN, EDWARDS e SUBLER, 2001).

De acordo com MONKIEDJE, ILORI e SPITELLER (2002) a aplicação de metalaxil e mefenoxam aumentou a comunidade bacteriana do solo, provavelmente, por tratar-se de fonte de $\mathrm{C}$ para alguns grupos de bactérias ou causar a liberação de outras fontes de nutrientes. Em solos da região sudeste do Brasil, MORETINI (2000) observou o mesmo efeito do metalaxil sobre a comunidade bacteriana. Segundo DROBY e COFFEY (1991) as bactérias não são afetadas pela aplicação desse fungicida, mas podem ser as responsáveis pelo desaparecimento da molécula no solo. Relataram também que o metalaxil atinge outras classes de fungos além daqueles para os quais foi sintetizado, o que é preocupante sob o ponto de vista ambiental.

As atividades enzimáticas dos solos também têm sido relatadas como potenciais indicadores de impactos negativos sobre o solo (DICK, 1992; BEYER et al., 1992; GARCIA et al., 1998; BROHON, DELOLME e GOURDON, 2001; SANNINO e GIANFREDA, 2001; QUILCAÑO e MARAÑÓN, 2002). As esterases, lipases e proteases que hidrolisam o diacetato de fluoresceína (FDA) são abundantes no solo e a capacidade de hidrolisar FDA é generalizada entre os fungos e bactérias. A quantificação da hidrólise fornece boa estimativa da atividade microbiana total. Os solos suplementados com metalaxil aos 7 dias de incubação apresentaram incremento não-significativo de $24 \%$ nessa atividade para a concentração de $3 \mu \mathrm{g} \mathrm{g}^{-1}$ (Figura 1). Para a maior concentração, o efeito foi de apenas 10\%. Aos 28 dias, o efeito positivo tornou-se significativo $(\mathrm{P}<0,01 \%)$ e proporcional à dose aplicada, chegando a patamares de 49 e $14 \%$ considerando a menor e maior dose, respectivamente.

No caso da suplementação com fenarimol (Figura 2), o incremento na atividade aos 7 dias foi visível em ambas as concentrações $( \pm 35 \%)$ e proporcional à dose aplicada. O pico de estimulação ocorreu aos 28 dias quando o incremento (significativo) alcançou porcentagens de 19 e $39 \%$ para a menor e maior dose, respectivamente. Somente para esse fungicida o efeito positivo manteve-se até os 119 dias de avaliação, quando na maior dose obteve-se incremento de $49 \%$. A atividade hidrolítica do diacetato de fluoresceína apresentou correlação significativa $(P<0,01 \%)$ com as atividades enzimáticas da fosfatase ácida e da desidrogenase.

Segundo SPESSOTO (2002) o metalaxil provocou mudanças na atividade total da microbiota em quatro solos avaliados, sendo três da região sudeste e um da região nordeste do Brasil. A microbiota presente no solo da região semi-árida do nordeste foi a que mais se beneficiou com a suplementação do solo, variando de 0,77 no início do experimento a 4,23 $\mu \mathrm{g}$ FDA hidrolisado $\mathrm{g}^{-1}$ de solo seco $\mathrm{min}^{-1}$ ao final de 70 dias de incubação. No solo avaliado neste trabalho, essa atividade variou de $3,07 \mu \mathrm{g}$ para $8,70 \mu \mathrm{g}$ FDA hidrolisado $\mathrm{g}^{-1}$ de solo seco $\operatorname{~min}^{-1}$ aos 42 dias de incubação considerando a suplementação 
com metalaxil na concentração de $30 \mu \mathrm{g} \mathrm{g}^{-1}$ de solo. No caso do fenarimol, considerando a maior dose e o mesmo período, a variação foi de 3,79 para 8,17 $\mu$ g FDA hidrolisado $\mathrm{g}^{-1}$ de solo seco min $^{-1}$. Observou-se pico de estimulação para ambos os fungicidas no $28^{\circ}$ dia de incubação. Nos outros períodos de avaliação não foi detectado efeito significativo dos fungicidas para essa atividade. Pelos resultados obtidos pode-se inferir que apesar de não-significativo, tanto o metalaxil quanto o fenarimol podem ter estimulado a produção do complexo enzimático que hidrolisa FDA.

A atividade enzimática da fosfatase também foi considerada por WICK et al. (2002) como indicador sensível da qualidade do solo. Em geral, a adição de fungicidas estimula a atividade dessa enzima (MONKIEDJE, ILORI e SPITELLER, 2002; NANNIPIERI, 1994). O efeito positivo da suplementação dos fungicidas metalaxil e fenarimol sobre a atividade da fosfatase ácida, observado apenas aos 7 e 28 dias de incubação (Figuras 1 e 2), não foi significativo. Estudos realizados com solos arenosos e argilosos demonstraram efeito estimulatório do mefenoxam e do metalaxil sobre a atividade enzimática da fosfatase ácida, sendo a transitoriedade da estimulação menor para o metalaxil (MONKIEDJE, ILORI e SPITELLER, 2002). Ainda assim, os autores consideraram de forma geral que os fungicidas aplicados nas concentrações de 1 a $200 \mu \mathrm{g} \mathrm{g}^{-1}$ de solo não afetaram a atividade enzimática da fosfatase.

As enzimas que hidrolisam o FDA e as fosfatases são ectoenzimas. A fosfatase ácida pode ser produzida tanto por microrganismos quanto pelas raízes das plantas. Sua atividade é influenciada pela disponibilidade de $\mathrm{P}$ inorgânico, ou pela formação de agregados com os componentes do solo (NANNIPIERI, CECCANTI e BIANCHI, 1988). Por serem extracelulares, geralmente, estão protegidas da degradação pela adsorção às argilas ou substâncias húmicas e assim podem se acumular. Essas enzimas imobilizadas pelos colóides do solo podem não ser tão sensíveis aos fungicidas como as associadas às células microbianas (NANNIPIERI, 1994). De acordo com CAMIÑA et al. (1998), as interações abióticas entre substratos e componentes do solo podem originar erros na estimativa da atividade enzimática.

Em solos de textura grossa, como os das regiões áridas e semi-áridas, as atividades de enzimas livres na solução do solo são praticamente negligenciáveis (BURNS, 1982). Em solos com alta porcentagem de areia e baixo conteúdo de matéria orgânica, como é o caso do solo em estudo, a atividade enzimática depende geralmente de enzimas intracelulares como, por exemplo, a atividade da desidrogenase (BURNS, 1982). Essa atividade enzimática é considerada indicador do metabolismo oxidativo dos solos e assim da atividade microbiana (SKUJINS, 1973). Tem sido usada como indicador da atividade microbiológica, tanto em solos áridos do Mediterrâneo (GARCIA, HÉRNANDES e COSTA, 1994) como em solos agrícolas de regiões mais úmidas (BEYER et al., 1992). MALKOME (1987), citado por DICK (1992), recomenda seu emprego em testes de rotina com agrotóxicos, uma vez que a atividade da desidrogenase permite determinar com sensibilidade a atividade microbiana dentro de 1 a 2 dias em experimentos de laboratório.

Pode-se observar (Figuras 1 e 2) que houve inibição não-significativa na atividade da desidrogenase em todos os tratamentos até o $7^{\circ}$ dia de incubação. No entanto, no $14^{\circ}$ dia foi observado incremento nessa atividade nos solos suplementados com os fungicidas. Tal efeito mostrou-se significativo apenas na maior dose do fenarimol $(64,0 \%)$, enquanto que para ambas as doses do metalaxil o maior aumento foi de $35 \%$. Do $42^{\circ}$ dia em diante houve inibição significativa $(P<0,01 \%)$ dessa atividade, chegando a 21 e $31 \%$ para as doses 1 e 2 do metalaxil e a 32 e $54 \%$ para o fenarimol. No final do período experimental, os resultados não apresentaram diferenças significativas devido recuperação dessa atividade, provavelmente, associada à recuperação da microbiota como evidenciado pelo Cmic. Resultados semelhantes foram obtidos por MONKIEDJE, ILORI e SPITELLER (2002). Segundo esses autores, os fungicidas metalaxil e mefenoxam inibiram severamente a atividade da desidrogenase durante todo o período experimental, seguindo o modelo dose-resposta. Neste estudo (com solos da região semi-árida brasileira), essa atividade foi inibida pelos fungicidas metalaxil e fenarimol nos primeiros sete dias de incubação em relação ao solo controle e apresentou pico de recuperação aos 28 dias. A atividade de desidrogenase voltou a declinar, provavelmente, devido a 
depleção de nutrientes uma vez que essa atividade correlaciona-se positivamente com o teor de matéria orgânica do solo (WLODARCZYK, STEPNIEWSKI e BRZEZINSKA, 2002). Tais resultados também estão de acordo com os obtidos por MORETINI (2000) para solos da região sudeste do Brasil. O autor observou inibição da atividade enzimática da desidrogenase pelo metalaxil nos sete primeiros dias, seguida de recuperação, comprovando a sensibilidade dessa atividade em detectar em curto prazo efeitos negativos sobre a microbiota do solo. A aplicação de outros fungicidas como, por exemplo, benomil e clorotalonil estimularam a atividade da desidrogenase (18-21\% e 8-15\%, respectivamente), enquanto que captam inibiu essa atividade em 40-58\% (CHEN e EDWARDS, 2001), demonstrando que os efeitos são específicos para cada fungicida.

\title{
4 CONCLUSÃO
}

Os fungicidas metalaxil e fenarimol apresentaram efeitos negativos sobre a microbiota de solos da região semi-árida brasileira, cultivados com uva. O efeito adverso foi demonstrado pelo Cmic, comprimento das hifas vivas e atividade da desidrogenase. Não foi observado efeito sobre o FDA e a atividade enzimática da fosfatase. $O$ fenarimol mostrou-se mais tóxico que o metalaxil e o efeito de ambos foi transitório no solo.

\begin{abstract}
EFFECT OF THE FUNGICIDES METALAXYL AND FENARIMOL IN SOIL MICROBIOTA

The adverse effects of the fungicides metalaxyl and fenarimol was evaluated on microbial community of soils cultivated with grapes in Petrolina region, Pernambuco State (Brazil). In the experiment carried out in greenhouse, the soils were enriched with different concentrations of the fungicides being evaluated the following microbiological parameters: microbial biomass $\mathrm{C}(\mathrm{Cmic})$, living hyphal length and hydrolytic activity of fluorescein diacetate (FDA), enzymatic activities of acid phosphatase and dehydrogenase. The results obtained with the supplementation of the fungicides showed that these compounds negatively affected of Cmic, the fungal living length and dehydrogenase activity, but it was not detected adverse effect on FDA and phosphatase activity. It was observed that fenarimol was more toxic than metalaxyl, and that the effects of both fungicides were transitory in the soil.
\end{abstract}

KEY-WORDS: FUNGICIDE; METALAXYL; FENARIMOL; SOIL MICROBIOTA.

\section{REFERÊNCIAS}

1 ALEF, K. Dehydrogenase activity. In: ALEF, K.; NANNIPIERI, P. (Ed.). Methods in applied soil microbiology and biochemistry. London: Academic Press, 1995. p. 228-231.

2 ALEF, K.; NANNIPIERI, P.; TRAZAR-CEPEDA. Phosphatase activity. In: ALEF, K.; NANNIPIERI, P. (Ed.). Methods in applied soil microbiology and biochemistry. London: Academic Press, 1995. p.335-344.

3 BEYER, L.; WACHENDORF, C.; BALZER, F.M.; BALZER-GRAF, U.R. The effect of soil texture and soil management on microbial biomass and soil enzyme activities in arable soils of Northwest Germany. Agrobiological Research, v.45, p.276-283, 1992.

4 BLOEM, J.; BOLHUIS, P.R.; VENINGA, M.R.; WIERINGA, J. Microscopic methods for counting bacteria and fungi in soil. In: ALEF, K.; NANNIPIERI, P. (Ed.). Methods in applied soil microbiology and biochemistry. London: Academic Press, 1995. p.162-173. 
5 BOEHM, M.J.; HOITINK, H. A.J. Sustenance of microbial activity in potting mixes and its impact of severity of Phytium root rot of Poinsettia. Phytopathology, v.82, p.259-264, 1992.

6 BROHON, B.; DELOLME, C.; GOURDON, R. Complementarity of bioassays and microbial activity measurements for the evaluation of hydrocarbon-contamined soils quality. Soil Biology and Biochemistry, v.33, p.883-891, 2001.

7 BURNS, R.G. Enzyme activity in soil: location and a possible role in microbial ecology. Soil Biology and Biochemistry, v.14, p.423-427, 1982.

8 CAMIÑA, F.; TRASAR-CEPEDA, C.; GIL-SOTRES, F.; LEIRÓS, C. Measurement of dehydrogenase activity in acid soils rich in organic matter. Soil Biology and Biochemistry, v.30, p.1005-1011, 1998.

9 CHEN, S.K.; EDWARDS, C.A. A microcosm approach to assess the effects of fungicides on soil ecological processes and plant growth: comparisons of two soil types. Soil Biology and Biochemistry, v.33, p.1981-1991, 2001.

10 CHEN, S.K.; EDWARDS, C.A.; SUBLER, S. Effects of the fungicides benomyl, captan and chlorothalonil on soil microbial activity and nitrogen dynamics in laboratory incubations. Soil Biology and Biochemistry, v.33, p.1971-1980, 2001.

11 DICK, R.P. A review: log-term effects of agricultural systems on soil biochemical and microbial parameters. Agriculture, Ecosystems and Environment, v.40, p.25-36, 1992.

12 DROBY, S.; COFFEY, M.D. Biodegradation process and nature of metabolism of metalaxyl in soil. Annals of Applied Biology, v.118, p.543-553, 1991.

13 GARCIA, C.; HÉRNANDEZ, T.; COSTA, F. Microbial activity in soils under Mediterranean environmental conditions. Soil Biology and Biochemistry, v.26, p.1185-1191, 1994.

14 GARCIA, C.; HÉRNANDEZ, T.; COSTA, F. Potential use of dehydrogenase activity as an index of microbial activity in degraded soils. Communications in Soil Science and Plant Analysis, v.1/2, p.123-134, 1997.

15 GARCIA, C.; HÉRNANDEZ, T.; ALBALADEJO, J.; CASTILLO, V.; ROLDAN, A. Revegetation in semiarid zones: influence of terracing and organic refuse on microbial activity. Soil Science Society of America Journal, v.62, p.670-676, 1998.

16 MELLONI, R.; CARDOSO, E.J.B.N. Quantificação de micélio extrarradicular de fungos micorrízicos arbusculares em plantas cítricas. I. Método empregado. Revista Brasileira de Ciência do Solo, v.23, p.53-58, 1999.

17 METALAXYL. Disponível em: <http://www.envisitrc.com/vivtox/database/pest/metalaxyl.htm>. Acesso em: 13 dez. 2004.

18 MONKIEDJE, A.; ILORI, M.O.; SPITELLER, M. Soil quality changes resulting from the application of the fungicides mefenoxam and metalaxyl to a sandy loam soil. Soil Biology and Biochemistry, v.34, p.1939-1948, 2002. 
19 MORETINI, A. Impacto do fungicida metalaxil sobre a microbiota e atividade enzimática do solo. São Paulo, 2000. 93 p. Dissertação (Mestrado em Biotecnologia), Universidade de São Paulo.

20 NANNIPIERI, P. The potential use of soil enzymes as indicators of productivity, sustainability and pollution. In: PANKHURST, C.E. (Ed.). Soil biota: management in sustainability farming systems. East Melbourne: CSIRO, 1994. p.224-238.

21 NANNIPIERI, P.; CECCANTI, B.; BIANCHI, D. Characterization of humus-phosphatase complexes extractec from soil. Soil Biology and Biochemistry, v.20, p.683-691, 1988.

22 NANNIPIERI, P.; GRECCO, S.; CECCANTI, B. Ecological significance of the biological activity in soil. In: BOLLAG, J..M.; STOTZKI, G. (Ed.). Soil biochemistry. New York: Marcel Dekker, 1990. v.6, p.293-355.

23 NEWMAN, E.I. A method for estimating the total length of root in a sample. Journal of Applied Ecology, v.3, p.139-145, 1966.

24 NOGUEIRA, M.A.; CARDOSO, E.J.B.N. Produção de micélio externo por fungos micorrízicos arbusculares e crescimento de soja em função de doses de fósforo. Revista Brasileira de Ciência do Solo, v.24, p.329-338, 2000.

25 PASCUAL, J.A.; GARCIA, C.; HERNANDEZ, T.; MORENO, J.L.; ROS, M. Soil microbial activity as a biomarker of degradation and remediation process. Soil Biology and Biochemistry, v.32, p.1877-1883, 2000.

26 QUILCANO, C.; MARAÑÓN, T. Dehydrogenase activity in Mediterranean forest soils. Biology and Fertility of Soils, v.35, p.102-107, 2002.

27 SANNINO, F.; GIANFREDA, L. Pesticide influence on soil enzymatic activities. Chemosphere, v.45, p.417-425, 2001.

28 SKUJINS, J. Dehydrogenase: an indicator of biological activities in arid soils. Bulletin of Ecological Research Communications, v.17, p.235-241, 1973.

29 SPESSOTO, A.M. Dissipação do fungicida metalaxil em solos brasileiros e caracterização genética por RAPD de isolados envolvidos no processo. São Carlos, 2002. 93 p. Tese (Doutorado em Ciências Biológicas), Universidade Federal de São Carlos.

30 VANCE, E.D.; BROOKES, P.C.; JENKINSON, D.S. An extraction method for measuring soil microbial biomass C. Soil Biology and Biochemistry, v.19, p.703-707, 1987.

31 VYAS, S.C. Nontarget effects of agricultural fungicides. Boca Raton: CRC Press, 1988. p.258-268.

32 WEETE, J.D. Structure and function of sterols in fungi. Advances in Lipid Research, v. 23, p.115-167, 1989.

33 WICK, B.; KÜHNE, R.F.; VIELHAUER, K.; VLEK, P.L.G. Temporal variability of selected soil microbiological and biochemical indicators under different soil quality conditions in south-western 
Nigeria. Biology and Fertility of Soils, v.35, p.155-167, 2002.

34 WLODARCZYK, T.; STEPNIEWSKI, W.; BRZEZINSKA, M. Dehydrogenase activity, redox potential, and emissions of carbon dioxide and nitrous dioxide from cambisols under flooding conditions. Biology and Fertility of Soils, v.36, p.200-206, 2002. 